\title{
Dexmedetomidine for prevention of postoperative pulmonary complications in patients after oral and maxillofacial surgery with fibular free flap reconstruction:a prospective, double-blind, randomized, placebo-controlled trial
}

\section{Yun Liu}

Peking University Third Hospital https://orcid.org/0000-0002-6821-7551

Xi Zhu (D 3917798@qq.com)

https://orcid.org/0000-0001-6091-8831

\section{Dan Zhou}

Peking University School of Stomatology

\section{Fang Han}

Peking University School of Stomatology

Xu Dong Yang

Peking University School of Stomatology

\section{Research article}

Keywords: Dexmedetomidine, Postoperative pulmonary complications (PPCs), Oral and maxillofacial surgery, Fibular free flap reconstruction, Tracheotomy

Posted Date: May 12th, 2020

DOI: https://doi.org/10.21203/rs.2.17094/v2

License: (c) (i) This work is licensed under a Creative Commons Attribution 4.0 International License. Read Full License

Version of Record: A version of this preprint was published at BMC Anesthesiology on May 27th, 2020. See the published version at https://doi.org/10.1186/s12871-020-01045-3. 


\section{Abstract}

Background: Postoperative pulmonary complications (PPCs) are common and significant problems for oral and maxillofacial surgery patients. Dexmedetomidine (DEX), an $a_{2}$-adrenoreceptor agonist, has been proven having lung protection effects. However, since now, there has not been final conclusion about whether DEX can reduce the incidence of PPCs. We hypothesize that, in oral and maxillofacial surgery with fibular free flap reconstruction patients, DEX may decrease the incidence of PPCs.

Methods: This was a prospective, double-blind, randomized, placebo-controlled, single-centered trial with two parallel arms. A total of 160 patients at intermediate-to-high risk of PPCs undergoing oral and maxillofacial surgery with fibular free flap reconstruction and tracheotomy were enrolled and randomized to receive continuous infusion of either DEX or placebo (normal saline). $0.4 \mathrm{ug} / \mathrm{kg}$ of DEX was given over 10 mins as an initial dose followed by a maintaining dose of $0.4 \mathrm{ug} / \mathrm{kg} / \mathrm{h}$ till the second day morning after surgery. At the same time, the normal saline was administered a similar quantity. The primary outcome was the incidence of PPCs according to Clavien-Dindo score within 7 days after surgery.

Results: The two groups had similar characteristics at baseline. $18(22.5 \%)$ of 80 patients administered DEX, and 32(40.0\%) of 80 patient administered placebo experienced PPCs within the first 7 days after surgery (relative risk [RR] 0.563,95\% confidence interval [Cl] 0.346-0.916; $P=0.017$ ). In the first 7 days after surgery, the DEX group had a lower incidence of PPCs and a better postoperative survival probability (Log-rank test, $P=0.019$ ), and was less prone to occur PPCs (Cox regression, $P=0.025, H R=0.516$ ). When the total dose of DEX was more than $328 \mu \mathrm{g}$, the patients were unlikely to have PPCs (ROC curve, AUC $=0.614, P=0.009$ ).

Conclusions: For patients undergoing oral and maxillofacial surgery with fibular free flap reconstruction and tracheotomy who were at intermediate or high risk of developing PPCs, continuous infusion of DEX could decrease the occurrence of PPCs during the first 7 days after surgery and shorten the length of hospital stay after surgery, but did not increase the prevalence of bradycardia or hypotension.

Trial registration: Chinese Clinical Trial Registry, www.chictr.org.cn, number: ChiCTR1800016153; Registered on May 15, 2018.

\section{Background}

Postoperative pulmonary complications (PPCs) are a composite of the hospital-acquired respiratory events after surgery, which are one of the major causes of morbidity, mortality, and prolonged hospital stay in patients after surgery ${ }^{1-3}$. Oral and maxillofacial surgery is considered one of surgical factors which most likely to interfere with respiratory function and strongly linked to PPCs ${ }^{4}$, especially radical oral and maxillofacial cancer surgery with microvascular free tissue transfer, such as fibular free flaps. Previous studies have demonstrated that the incidence of PPCs after head and neck surgery with free flap surgery is $18.8 \%$ to $44.8 \%{ }^{4-8}$, while in patients following major head and neck surgery with tracheostomy 
can be up to $47 \% \%^{6,9}$. Therefore, it is necessary to prevent and reduce the occurrence of PPCs in patients undergoing oral and maxillofacial surgery, which is a specific surgical sub-cohort within head and neck surgery, with fibular free flap reconstruction and tracheostomy.

Dexmedetomidine(DEX) is a new highly selective $\mathrm{a}_{2}$ adrenoceptor agonist which has anxiolysis, sedation, and modest analgesia with minimal respiratory depression effects ${ }^{10}$ and has been widely and safely used in oral and maxillofacial surgeries ${ }^{11}$. Studies have proved that DEX could attenuate perioperative stress, inflammation, and protect the immune function of surgical patients ${ }^{12}$, and can provide clinically postoperative pulmonary relevant benefits by improving oxygenation and lung mechanics ${ }^{13,14}$, all of which may contribute to decreased postoperative complications and improved clinical outcomes. In the last few years, a few clinical trials have evaluated the effect of DEX on PPCs ${ }^{13-19}$. However, the results of these studies are markedly variable and appear to be underpowered. So, since now, there has not been final conclusion about whether or not DEX can reduce the incidence of PPCs. As for the effect of DEX on PPCs in oral and maxillofacial surgeries, none of clinical trials have ever involved.

The purpose of the present study was to investigate whether DEX can reduce the incidence of PPCs during the initial 7 postoperative days in patients undergoing oral and maxillofacial surgery with fibular free flap reconstruction and tracheotomy who are at intermediate-to-high risk for PPCs.

\section{Methods}

\subsection{Trial design}

We did this prospective, double-blind, randomized, placebo-controlled, single-center, clinical trial in the department of anesthesiology of Peking University Hospital of Stomatology, a tertiary academic hospital in Beijing, China. The ethics was approved by Peking University Hospital of Stomatology Biomedical Ethics Committee (Number: PKUSSIRB-201735060) on January 26, 2018. The trial was registered with Chinese Clinical Trial Registry, www.chictr.org.cn (Number: ChiCTR1800016153) on May 15, 2018. Written informed consent was obtained from all participating patients or their next of kin or legal representative who must understand the recruiter's description of the trial. The main aim of the study was to evaluate the supremacy of the intervention. Entitled patient were enlisted and arbitrarily designed to benefit one of the interventions, DEX or placebo (normal saline).

\subsection{Randomization and Blinding}

A biostatistician from Peking University Third Hospital, who was independent of data management and statistical analyses, generated random numbers (in a 1:1 ratio) using the SAS 9.2 software (SAS Institute, Cary, NC, USA). The results of randomization were sealed in sequentially numbered envelopes.

Throughout the survey period, enlisted patients were unpremeditated chosen to obtain DEX or placebo. A survey anesthesiologist, according to the arbitrarily series those not taking part in the survey applied the survey medicine. 
The investigators, health-care team members (including the attending anesthesiologists, surgeons, nurses and the physicians for postoperative follow-up) and patients were blind to the treatment group assignment throughout the study period. In case of emergency, (such as development of severe adverse events, persistent hemodynamic instability or rapid deterioration of the patient's clinical status), the attending anesthesiologist could request to unmask the allocation, and adjust or even stop study drug infusion if necessary. These non-blind situations were documented, but the final analyses were performed on the intention-to-treat population.

\subsection{Participants}

Patients were included if they (1) were scheduled for oral and maxillofacial surgery with fibular free flap reconstruction that was expected to exceed 3 hours under general anesthesia, (2) were 51 years old or over, (3) took tracheotomy before the end of the surgery, (4) had an intermediate to high risk of developing PPCs judged by Assess Respiratory Risk in Surgical Patients in Catalonia (ARISCAT) score ${ }^{20}$ ( cumulative ARISCAT risk score were 26 or greater) (Additional file 1).

Patients were excluded if they met the following criteria: (1) body mass index of 35 or higher, (2) allergic to DEX, (3) recent sedatives-taking history, (4) sick sinus syndrome, or severe sinus bradycardia( $<50$ beats per min[bpm]), or second degree or greater atrioventricular block without pacemaker, (5) previous lung surgery history, or severe chest wall malformation, or acute exacerbation of chronic obstructive pulmonary disease (AECOPD), or uncontrolled asthma (Asthma control test $\leq 18$ ), or pulmonary artery stenosis, or pulmonary hypertension, (6) complex heart deformities, congestive heart failure, or known preoperative left ventricular ejection fraction less than $30 \%$, (7) serious hepatic dysfunction(Child-Pugh class $\mathrm{C}$ ), or serious renal dysfunction(requirement of renal replacement therapy), (8) a history of mental illness, (9) refused to participate in the clinical trial.

\subsection{Interventions, anesthesia and perioperative management}

The study drug DEX, dexmedetomidine hydrochloride injection $2 \mathrm{ml}: 0.2 \mathrm{mg}$ (manufactured by Yangtze River Pharmaceutical (Group) Co., Ltd, Jiangsu, China), was diluted with normal saline to $50 \mathrm{~mL}$ (the final concentration of DEX was $4 \mu \mathrm{g} / \mathrm{mL}$ ) by a nurse, who did not participate in the rest of the study, before administration. The study drug (diluted DEX) and placebo drug \normal saline $\Downarrow$ were all provided as clear aqueous solution in the same $50 \mathrm{ml}$ injection syringes and dispensed according to the randomization results. The two drugs were given as an initial dose of $0.1 \mathrm{ml} / \mathrm{kg}(0.4 \mu \mathrm{g} / \mathrm{kg}$ of DEX in the treatment group) over $10 \mathrm{~min}$ followed by a maintenance dose of $0.1 \mathrm{ml} / \mathrm{kg} / \mathrm{h}(0.4 \mu \mathrm{g} / \mathrm{kg} / \mathrm{h}$ of DEX in the treatment group) from the beginning of anesthesia induction on the day of surgery until $0600 \mathrm{~h}$ on the first day after surgery.

All patients followed the similar anesthesia and perioperative management regimen. Half an hour before the beginning of the surgery, prophylactic antibiotics (mostly cefuroxime $1.5 \mathrm{~g}$, the second-generation cephalosporin) were routinely administered and apply once more at the fourth hour within the operation time when the surgery time was longer than four hours. After surgery, routine antibiotics with cefuroxime 
$1.5 \mathrm{~g}$ twice a day and ornidazole $0.5 \mathrm{~g}$ twice a day for 6 days were administered. The choice and the duration of antibiotics treatment were decided according to the Guiding Principles of Clinical Use of Antibiotics (2015 edition) which was published by Chinese National Health and Family Planning Commission in 2015.

Perioperative monitoring included continuous 5-lead electrocardiogram, pulse oxygen saturation, noninvasive blood pressure, Train-of-Four ratio (TOF, T4/T1) for measuring the level of neuromuscular blockade, Bispectral Index (BIS) (Covidien, USA) value, end-tidal carbon dioxide concentration $\left(\mathrm{EtCO}_{2}\right)$, airway pressure, axillary temperature, urine output. Intra-arterial pressure was also monitored through cannulation of the arteria dorsalis pedis (on the opposite of the surgical leg) immediately after anesthesia induction.

All patients were performed general anesthesia with nasotracheal intubation. Anesthesia was induced in both groups with $0.05 \mathrm{mg} / \mathrm{kg}$ midazolam, $0.3 \mu \mathrm{g} / \mathrm{kg}$ sufentanil, $2 \mathrm{mg} / \mathrm{kg}$ propofol, and $0.6 \mathrm{mg} / \mathrm{kg}$ rocuronium, and maintained with target-controlled infusion (TCl) of propofol (2 to $6 \mu \mathrm{g} / \mathrm{ml}$ plasma concentration) and remifentanil ( 0.5 to $6 \mathrm{ng} / \mathrm{ml}$ plasma concentration), without inhalational sevoflurane and nitrous oxide. During operation, in accordance with hemodynamic state, surgical steps and TOF ratio, additional analgesia was administered by applying boluses of sufentanil 0.1 to $0.5 \mu \mathrm{g} / \mathrm{kg}$ and muscle relaxation was achieved by intermittent injection of rocuronium $10 \mathrm{mg}$ each time. BIS value was maintained between 40 and 60 .

Volume-controlled mechanical ventilation was established with the fraction of inspiration $\mathrm{O}_{2}\left(\mathrm{FiO}_{2}\right)$ from 0.4 to 0.6 , the tidal volume from 6 to $8 \mathrm{ml} / \mathrm{kg}$ (ideal weight), the positive end-expiratory pressure (PEEP) 5 $\mathrm{cm} \mathrm{H}_{2} \mathrm{O}$. The respiratory rate was adjusted to maintain $\mathrm{EtCO}_{2}$ between 35 and $45 \mathrm{mmHg}$.

Fluid management was performed according to routine practice with crystalloids - sodium lactate ringer's injection and/or colloids - $6 \%$ hydroxyethyl starch (HES) 130/0.4 sodium injection. Packed red blood cells were transfused while the hemoglobin level was lower than $7 \mathrm{~g} / \mathrm{dl}$.

Before the end of the surgery, all patients underwent tracheotomy after spontaneous breathing recovery (TOF ratio > 0.9). After surgery, all patients were transferred to the postoperative care unit (PACU) and supervised until $0830 \mathrm{~h}$ on the first day after surgery before sent back to the general wards.

During the postoperative period, intravenous patient-controlled analgesia with sufentanil $1.0 \sim 1.5 \mathrm{ug} / \mathrm{kg}$ and tropisetron $10 \mathrm{mg}$ was provided for up to 48 hours. All patients were given aerosol inhalation with ambroxol $60 \mathrm{mg}$ and hydrocortisone $4 \mathrm{mg}$ three times a day before discharge and mechanical vibration sputum expectoration (TC Juhnson) three times a day for 5 days. Usually on the fifth day after surgery, the tracheostomy tube was removed after the oral and maxillofacial surgeons evaluating the situation of the airway and operation area. Other treatments including early mobilization (routinely on the fourth postoperative day), anticoagulant therapy (routinely 5 days, with aspirin or low molecular heparin), enteral and parenteral nutrition were administered according to routine practice. 
The adverse events (bradycardia and hypotension) were monitored and documented throughout the period of study drug infusion. Bradycardia was defined as heart rate less than 50 beats/min or a decrease of more than $20 \%$ from baseline. Hypotension was defined as systolic blood pressure less than $90 \mathrm{~mm} \mathrm{Hg}$ or a decrease of more than $20 \%$ from baseline. Intervention for bradycardia included administration of medication (atropine mostly) or adjustment of study drug infusion, or both. Intervention for hypotension included intravenous fluid bolus, or administration of vasoactive drugs (ephedrine, methoxamine, etc.) or adjustment of study drug infusion. All interventions were recorded.

\subsection{Outcomes}

The postoperative daily follow-up period was 7 days. Research members who were trained before the study and not involved in the clinical care of patients did the outcome assessment.

\section{Primary outcome}

The primary outcome was the incidence of PPCs within 7 days after surgery. PPCs was defined as any preselected complication occurred, which included respiratory infection, respiratory failure, pleural effusion, atelectasis, pneumothorax, bronchospasm, aspiration pneumonitis, pulmonary edema, pulmonary embolism, and acute respiratory distress syndrome. The diagnostic criteria of each individual PPCs were similar with those used in the previous studies ${ }^{1-3}$ (Additional file 2). We chose the ClavienDindo Classification ${ }^{21}$ to categorize PPCs into five major groups (Additional file 3). In our study, PPCs of grade II or above were considered to calculate the incidence of PPCs. The diagnosis of PPCs was made by the attending medical team (anesthesiologists, Intensive Care Union physicians, or respiratory physicians). The physicians diagnosed PPCs according to patients' medical history, clinical physical examination, conventional monitoring value, laboratory results, image examination, and so on. If a PPC occurred, the date of earliest diagnosis and the evidences according to which the diagnosis was made were documented.

\section{Secondary outcomes}

The secondary outcomes were as follows: (1) the time to first diagnosis of PPCs - indicated the time from end of surgery to first diagnosis of PPCs within 7 days after surgery; (2) the number of PPCs - indicated the number of diagnosed individual PPCs within 7 days after surgery; (3)the dose-effect relationship between DEX and PPCs; (4) the incidence of postoperative extrapulmonary complications - defined as complications other than PPCs that occur during operation and within 7 days after surgery, and require therapeutic intervention, included delirium - assessed by the Confusion Assessment Method for the ICU $(\mathrm{CAM}-\mathrm{ICU})^{10}$, anemia - defined as hemoglobin less than $9 \mathrm{~g} / \mathrm{dL}$, extrapulmonary infection; (5) the unexpected need for secondary surgery (hematoma or vascular crisis exploration); (6) the adverse events (bradycardia, hypotension) during the period of study drug infusion; (7) length of stay in hospital after surgery; (8) 30-day all-cause mortality.

\subsection{Sample size and Statistical methods}


We used the excellent effect test of two groups of independent sample rate to calculate the sample size. According to the literature data ${ }^{16}$, the sample size was calculated according to the incidence of postoperative pulmonary complications. The incidence was $3.89 \%$ in the experimental group (DEX group) and $17.99 \%$ in the control group. The class I error of hypothesis test was 0.025 , the class II error was 0.2 , and the proportion of sample size between the test group and the control group was 1:1. The sample size was calculated by Stata 10.0 software According to the bilateral test formula of sample size: $\mathrm{n}=2 \times\left(\mathrm{U}_{\mathrm{a}}\right.$ $\left.+U_{\beta}\right)^{2} \times P(1-P) / \delta^{2}, \delta$ was set to 0.01 . The sample size of the test group was 64 and that of the control group was 64 . Taking into account the dropout rate of $20 \%$, each group requires a sample size of 76.8 , so we planned to enroll 160 patients (80 for each group) in all.

We analysed outcome data and safety in the intention-to-treat population. Statistical analyses were performed on SPSS version 24.0 software (SPSS, Chicago, IL, USA) and P values less than 0.05 were considered to be of statistical significance. Statistical description was provided for baseline data such as demographic variables, medical history, perioperative medications, and perioperative management. For primary outcome (the incidence of PPCs with 7 days after surgery), the effect of the intervention was reported as number and percentage and estimated with relative risk and $95 \%$ confidence interval and the $\chi 2$ test for hypothesis testing. For secondary outcomes, continuous variables with normal distribution were analyzed using an unpaired $t$ test; continuous variables with abnormal distribution or ranked data were analyzed by Mann-Whitney $U$ test; categorical variables were analysed with the $\chi 2$ test, continuity correction $\chi 2$ test or Fisher exact test. Time-to-event results were calculated with the Kaplan-Meier estimator, and the differences between groups were assessed by the log-rank test. And, Cox regression was used for survival analysis. For dose-effect relationship, receiver operating characteristic (ROC) curve was used for calculating the $P$ and cutoff values.

\section{Results}

\subsection{Participant flow and recruitment}

Between September 3, 2018 and July 31, 2019, a total of 624 patients who were scheduled for oral and maxillofacial surgery with free flap reconstruction were screened for study participation; of these, 160 patients were enrolled into the study and randomly assigned to receive either DEX $(n=80)$ or placebo $(n=80)$. Study drug infusion was modified in 9 patients because of adverse events. 3 patients were discharged from the hospital within 7 days after surgery. There were no lapses in the blinding. All patients were included in the final intention-to-treat analyses (Figure 1). The final follow-up of the last randomized patient was finished on August 31, 2019.

\subsection{Baseline patient demographic and perioperative characteristics}

Overall, the two groups were well matched for all the variables.

Both baseline patient demographic and preoperative characteristics share the same features. (Table 1). 
For intraoperative and postoperative characteristics (Table 2, Table 3), the intraoperative dosages of propofol and remifentanil in the DEX group were significantly lower than the placebo group $(P<0.01)$, and numeric rating scale (NRS, an 11 points scale where 0 indicated the best and 10 indicated the worst) of pain for oral and maxillofacial and fibular areas on the first day after surgery were both significantly lower in the DEX group than in the placebo group $(P<0.01)$, as well as the sleep time on the first day after surgery in the DEX group was longer than the placebo group $(P<0.01)$. At the same time, intraoperative urine output and total infusion on the second day after surgery were different in the two groups, too $(\mathrm{P}<$ 0.05).

\subsection{Primary outcome and secondary outcomes}

On the whole, PPCs within the first 7 days after surgery occurred in $18(22.5 \%)$ of 80 patients given DEX, and in $32(40.0 \%)$ of 80 patients given placebo (relative risk [RR] 0.563, 95\% confidence interval [Cl] 0.3460.916; $\mathrm{P}=0.017$ ) (Table 4).

Although without numerical difference, the most common PPCs was respiratory infection, accounted for 14(17.5\%) patients in DEX group liken to 19(23.8\%) patient in placebo group ( $P=0.329)$. The incidence of the other PPCs (included respiratory failure, pleural effusion, atelectasis, pneumothorax, bronchospasm, aspiration pneumonitis, pulmonary edema, pulmonary embolism, and acute respiratory distress syndrome) was low and also without statistical difference between the two groups ( $P>0.05)$.

The secondary outcomes appeared in Table 4. The incidence of one kind of PPC was less common in DEX group (RR $0.541,95 \% \mathrm{Cl} 0.314-0.933 ; \mathrm{P}=0.023$ ), and the length of stay in hospital after surgery was shorter in DEX group ( $P=0.036)$. Nevertheless, the time to first diagnosis of PPCs, the incidence of two PPCs, the incidence of extrapulmonary complications (delirium, anemia, extrapulmonary infection), the need of secondary surgery, the incidence of adverse events (bradycardia, hypotension) and the 30-day allcause mortality did not significantly differ between groups.

The Kaplan-Meier curves representing PPCs in the postoperative 7 days between the DEX group and the placebo group were shown in Figure 2. The small plus sign indicated deletion, since most of the observed objects did not have an ending at 7 days after surgery. The Log rank test results were shown in Table 5 $(P=0.019)$. Therefore, the DEX group had a lower incidence of PPCs in the first 7 days after surgery.

The Cox regression results were shown in Table $6(P=0.025, H R=0.516)$. Hence, within the first 7 postoperative days, the DEX group was less prone to occur PPCs.

The ROC curve results were shown in Figure 3 and Table 7. The area under the ROC curve (AUC) was $0.614, P=0.009<0.05$, indicating that the cutoff value made by the ROC curve was statistically significant in predicting the incidence of PPCs. The sensitivity and specificity were respectively $78.00 \%$ and $49.09 \%$ and the cutoff value was 328. Hence, when the total dose of DEX on operation day was no more than $328 \mu \mathrm{g}$, the patients might have PPCs postoperatively, and when DEX was more than $328 \mu \mathrm{g}$, PPCs were unlikely to occur. 


\section{Discussion}

Our results suggested that DEX infusion greatly decreased the occurrence of PPCs (including respiratory infection, respiratory failure, pleural effusion, atelectasis, pneumothorax, bronchospasm, aspiration pneumonitis, pulmonary edema, pulmonary embolism, and acute respiratory distress syndrome) during the first 7 days after surgery. At the same time, DEX administration also significantly reduced the incidence of one kind of PPC and shortened the length of stay in hospital after surgery. Moreover, In the first 7 days after surgery, the DEX group had a lower incidence of PPCs and was less prone to occur PPCs. Furthermore, when the total dose of DEX was more than $328 \mu \mathrm{g}$, the patients were unlikely to have PPCs.

Our finding was in accordance with the previous randomized controlled clinical studies by Meiyue Liu in $2018^{16}$ (3.89\% vs. $\left.17.99 \%, P<0.05\right)$ about the effects of DEX on PPCs (including hypoxemia, atelectasis and lung infection) in elderly patients undergoing spinal surgery. However, conflicting results in other studies still existed. In 2016, Su Hyun Lee ${ }^{13}$ showed that patients with moderate COPD undergoing lung cancer surgery in DEX group had fewer incidence of PPCs, including atelectasis ( $0 \%$ vs. $16 \%, P=0.110)$, focal lung infiltration ( $4 \%$ vs. $8 \%, P>0.99)$ and acute lung injury ( $0 \%$ vs. $4 \%, P>0.99)$ by improving oxygenation and lung mechanics, but there was no statistical difference $(P>0.05)$. In 2016, Rabie Soliman ${ }^{15}$ found in high-risk patients undergoing aortic vascular surgery, DEX can not reduce the occurrence of PPCs (including infection and edema, $\mathrm{P}=0.999$ ), either. In 2017 , Xue $\mathrm{Li}^{17}$ found that the incidence of PPCs (including pulmonary infection, pneumothorax and pleural effusion) tended to be lower in the DEX group than in the control group (OR $0.51,95 \% \mathrm{Cl} 0.26$ to $1.00 ; p=0.050$ ) in elderly patients after cardiac surgery. In 2019, Li-Yun Zhang ${ }^{18}$ indicated that there were no significant differences in PPCs(including atelectasis, pneumonia and air leak) between DEX and control groups $(P>0.05)$ in patients receiving robotic-assisted thoracic surgery.

In addition, our survey revealed the most common PPCs was respiratory infection, registering 14(17.5\%) patient in DEX group in comparison with 19 (23.8\%) in placebo group. Occurrence of postoperative respiratory infection was the same with the retrospective study in 2015 about 482 patients undergoing oral cancer surgery with tracheotomy ${ }^{6}$ and the retrospective analysis of 331 cases after oral and maxillofacial surgery with or without free flap construction in $2017^{22}$. Previous studies had showed that multiple variables including advanced age, male sex, poor underlying medical condition, surgery location, a higher American Society of Anesthesiologists (ASA) grade, tracheotomy and reintubation were associated with an increased risk of postoperative pneumonia ${ }^{22}$. All our patients were older than 51 years and underwent tracheotomy, and most of our patients were male $(63.8 \%$ vs. $36.3 \%, 66.3 \%$ vs. $33.8 \%$, respectively), which could have been responsible for the high incidence of postoperative pneumonia in our study. But, the incidence of the other PPCs (included respiratory failure, pleural effusion, atelectasis, pneumothorax, bronchospasm, aspiration pneumonitis, pulmonary edema, pulmonary embolism, and acute respiratory distress syndrome) in our study was low. This was different from the latest two studies in JAMA 2019, which showed that respiratory failure was the most common PPC ${ }^{2,3}$. 
Oral and maxillofacial surgery was a specific surgical sub-cohort within head and neck surgery, which was considered high risk of PPCs ${ }^{23}$. The fibular free flap was one of the most frequently used free flaps in oral and maxillofacial surgery, which was used for reconstruction of bony or composite defects 5 . In oral and maxillofacial surgery, patients after surgery might be highly impacted with after affect owing to swallowing and coughing, due to the body specific stance, organs of swallowing and breathing. This hinders airway which might cause the incident of PPCs as an outcome ${ }^{24}$. Moreover, this type of surgery had long surgical time or mechanical ventilation time (mostly more than 3 hours), which might cause ventilation induced lung injury (VILI) ${ }^{25}$, and had limb ischemia-reperfusion injury due to the use of the tourniquet in the thigh area, which might induce remote lung damage ${ }^{26}$. Except that, after the type of surgery, due to the microvascular reconstruction technique in the neck region, patients are required to stay lying in bed restraining lots of neck movement for at least three days after surgery, which might bring about respiratory muscle complications and mouth ejection and even PPCs ${ }^{27}$. Thus, one might expect a high rate of PPCs after oral and maxillofacial surgery, which had been proven in previous studies ${ }^{5,7,8}$. In our study, PPCs developed in 40.0\% (32 of 80 ) of oral and maxillofacial surgery with tracheotomy patients in the placebo group, largely in agreement with the prospective, randomized, controlled trial study about major head and neck surgery with tracheostomy $(47 \%)^{9}$, but much higher than the retrospective analysis of 648 cases about major oral and maxillofacial surgery with microvascular reconstruction $(18.8 \%)^{5}$. To this conflict, we considered the risk of tracheotomy might be the main cause, but this needed more proofs. On the other hand, our data further supported the evidence that oral and maxillofacial surgery was associated with a high risk of PPCs.

Although DEX was generally well tolerated, it could cause concentration related adverse circulatory effects (e.g. bradycardia and hypotension) ${ }^{28}$. However, the relationship between the dose use/ the mode of DEX administration (a single-bolus injection, a continuous infusion, or both in combination) and cardiac side-effects had not been established ${ }^{29}$. In our study, the median (IQR) of age of the two groups was $59(55,65)$ and $62(56,67)$ years, so in consideration of concentration related adverse circulatory effects for elderly patients, we chose a $0.4 \mu \mathrm{g} / \mathrm{kg}$ infusion over $10 \mathrm{~min}$, followed by a dose of $0.4 \mu \mathrm{g} / \mathrm{kg} / \mathrm{h}$ to maintain the anesthesia. The similar low DEX infusion dosing could be found in many other studies $^{10,30-32}$. And our study also indicated that this dose of DEX continuous infusion did not increase the prevalence of bradycardia or hypotension, so we thought that our DEX dose was proper for safety evaluation.

A systematic review and meta-analysis in BMJ indicated that postoperative pulmonary complications typically took place within the first week after surgery ${ }^{33}$, and it had been proved that the time between surgery and the first postoperative pulmonary complication was about 3 (2 to 6 ) days ${ }^{34}$. These conclusions were similar in our study, in which the first time of diagnosis of PPCs was 4 (2 to 5) days in DEX group and 3 (2 to 5 ) days in control group. We assumed that DEX infusion could alleviate the lung injury during the infusion time by reducing inflammation and stress, as well as protecting the immune function ${ }^{35}$. But the effects of DEX on clinical outcomes, such as PPCs, would gradually emerge after DEX 
termination. There had been a great number of clinical studies which demonstrated that perioperative DEX administration had benefits about long term (e.g. postoperative 30 days ${ }^{17}$, even 3 years ${ }^{36}$ ) clinical outcomes. In consequence, we chose a time frame of postoperative 7 days about primary outcome assessment. And this could explain why the Kaplan-Meier analysis of the present RCT the most profound difference between groups occurred after the postoperative day 4 (long after DEX termination).

It started becoming clear that there were contrast between those above surveys looking back to the overview of contrast and similarities, including the study population, the surgery type, the diagnostic criteria of PPCs, the observation time of PPCs, the dose of DEX, and so on. Therefore, our study was the first prospective clinical trial about the relationship between DEX and PPCs in patients undergoing oral and maxillofacial surgery with microvascular reconstruction and tracheotomy.

So far, the evidence on the accurate mechanisms of the effects about DEX on PPCs remained poorly understood, because of the complex etiology and pathophysiology and different diagnosis criteria of PPCs. A number of previous animal and clinical studies had tried to reveal the various mechanisms which might contribute to the lung protective effect of DEX. First, DEX, as a new highly selective $a_{2}$ adrenergic receptor agonist, could alleviate lung injury by improving ventilation/perfusion ratio and oxygenation by directly stimulating $a_{2 B}$ receptors in lung vascular smooth muscles ${ }^{14}$. Second, DEX had direct protective effects on airway. An animal experiment in dogs reported that DEX had a bronchodilator effect in histamine-mediated bronchospasm ${ }^{37}$, as well as a study in guinea pig improved that DEX had a direct airway smooth muscle effect and an underlying mechanism for cough suppression by inhibiting acetylcholine releasing from cholinergic nerves ${ }^{38}$. Third, inflammation was an important cause of lung injury. Various studies had showed that DEX could suppress systemic inflammatory processes by downregulation the signaling pathway of HMGB1-TLR4-MyD88-MARK- NF-KB and inflammatory mediators of IL-1, IL-4, IL-6, IL-8 and TNF-a, etc. ${ }^{35,39}$ by activating $a_{2}$ adrenergic receptors and stimulating the vagus nerve via a vagal and $a_{7}$ nicotinic acetylcholine receptor-dependent mechanism ${ }^{40}$. Fourth, DEX had been demonstrated to have lung protective effects by reducing dead space ventilation, increasing dynamic compliance ${ }^{13}$, so this point also might be one of the reasons why DEX could decrease PPCs in our study. Fifth, propofol, which was the main anesthetic during operation in anesthesia maintain period in our study, was reported to have a higher rate of PPCs compared with inhaled anesthetics sevoflurane ${ }^{41}$. In our study, the amount of propofol was significantly lower in the DEX group than in the placebo group, so we might conclude that, after intravenous infusion of DEX, the decreasing demand for propofol had a beneficial effect of reducing the incidence of PPCs. Six, our results showed a significant difference in intraoperative remifentanil consumption between the two groups, which could be explained that the lower opioid consumption in the DEX group was caused by the analgesic effect of DEX. Remifentanil was an ultra-short-acting, potent opioid analgesic. Previous studies showed that remifentanil could attenuate inflammation and acute lung injury through signaling pathway ${ }^{42,43}$. So, in our study, the lower occurrence of PPCs in DEX group might be in connection with the lessened amount of remifentanil. Seven, Ahmed Hasanin in $2018^{44}$ supposed in his paper that the improvement of lung 
mechanics might be due to the potential better sedation state of DEX administration to have better relaxation of the chest wall, but this needed further proofs. However, overall speaking, all those above assumptions required further evaluation in more studies with higher level of evidence.

Apart from DEX-induced improvements in PPCs and postoperative length of stay in hospital, our study also found that on the first day after oral and maxillofacial surgery, DEX alleviated the subjective pain in both oral and maxillofacial area and fibular area, and increased the objective sleep time. These results were similar with the clinical trial in Lancet by Su Xian in $2016^{10}$. The analgesia effect of DEX was worked by acting on the $a_{2}$ adrenergic receptors in the spinal cord ${ }^{45}$. The hypnotic properties of DEX was exerted by activating the endogenous sleep-promoting pathway and producing a stage II non-rapid eye movement sleep-like state ${ }^{46}$.

Besides, previous study had confirmed that prophylactic DEX significantly decreased the occurrence of delirium during the first 7 days after non-cardiac surgery ${ }^{10}$. However, in our study, we found that patients in the DEX group had less delirium incidence than patients in the placebo group (1.3\% vs. $5.0 \%$; RR 0.250 , $\mathrm{Cl}$ 0.029-2.188; $\mathrm{P}=0.173$ ), but without statistical difference. We inferred the reason might be our sample size was not big enough considering the low incidence of postoperative delirium in our study population.

The survey had a lot of limitations. (1) The study was only designed to investigate differences in postoperative clinical practice (incidence of PPCs), but lack of research of the effect of DEX on biological markers (in plasma or bronchoalveolar lavage fluid) about lungs damages and indicators about respiratory dynamics throughout the perioperative time. (2) Regarding the high hospital cost, serum concentration of DEX wasn't calculated. (3) This trial only studied one kind of transfusion speed and one administration way of DEX, so different transfusion speeds and different administration ways should be further investigated. (4) The finding of ROC curve analysis was not that robust, so the finding of the doseeffect relationship between DEX and PPCs can be considered valid only for this specific clinical setting. (5) Since our study was the first clinical trial to evaluate the influence of DEX on the incidence of PPCs in patients undergoing oral and maxillofacial surgery, and we did not conduct a pilot study, the sample size calculation which we referred to the relevant data of patients undergoing spinal surgery might not be very accurate. Fortunately, the positive result was obtained in this study. However, future larger sample size clinical trials are needed to verify our findings. (6) Due to the complex and various definition of PPCs and the hospital where we carried out this study is a specialized Stomatological hospital, the improper estimation of PPCs did exist. Therefore, further research in the future will take the above factors into account.

\section{Conclusion}

For patients undergoing oral and maxillofacial surgery with fibular free flap reconstruction and tracheotomy who were at intermediate or high risk of developing PPCs, continuous infusion of DEX could decrease the occurrence of PPCs during the first 7 days after surgery and shorten the length of hospital 
stay after surgery, but did not increase the prevalence of bradycardia or hypotension. In consideration of the limitations in our study, a larger sample size may be required to verify the difference in the future.

\section{Abbreviations}

Postoperative pulmonary complications (PPCs); Dexmedetomidine (DEX); relative risk (RR); confidence interval (Cl); Assess Respiratory Risk in Surgical Patients in Catalonia (ARISCAT); acute exacerbation of chronic obstructive pulmonary disease (AECOPD); Train-of-Four (TOF); Bispectral Index (BIS); end-tidal carbon dioxide concentration $\left(\mathrm{EtCO}_{2}\right)$; target-controlled infusion ( $\mathrm{TCl}$ ); fraction of inspiration $\mathrm{O}_{2}\left(\mathrm{FiO}_{2}\right)$; positive end-expiratory pressure (PEEP); hydroxyethyl starch (HES); postoperative care unit (PACU); numeric rating scale (NRS); ventilation induced lung injury (VILI); American Society of Anesthesiologists (ASA); Confusion Assessment Method for the ICU (CAM-ICU); receiver operating characteristic (ROC); area under the ROC curve (AUC); interquartile range (IQR); body mass index (BMI); New York Heart Association (NYHA); oxygen saturation as measured by pulse oximetry (SpO2); Hemoglobin ( $\mathrm{Hb}$ ); chronic obstructive pulmonary disease (COPD).

\section{Declarations}

\subsection{Ethics approval and consent to participate}

Ethical approval was received from the Biomedical Ethics Committee of Peking University Hospital of Stomatology (Number: PKUSSIRB-201735060) in January 26, 2018.

Written informed consent was obtained from all participating patients or their next of kin or legal representative who must understand the recruiter's description of the trial

\subsection{Consent for publication}

Not applicable.

\subsection{Availability of data and materials}

The datasets generated and/or analyzed during the current study will be available from the corresponding author on a reasonable request.

\subsection{Competing interests}

The authors declare that they have no competing interests.

\subsection{Funding}

This work was supported by National Natural Science Foundation of China 
(81372043), Beijing Natural Science Foundation (7162199), and National Science

and Technology Major Project (2018ZX10101004). All the funding bodies had no role in study design, data collection and analysis, decision to publish or preparation of the manuscript.

\subsection{Authors' contributions}

$Y L$ and $X Z$ contributed to the study concept and design.

YL, DZ and FH contributed to acquisition of data.

YL and XDY contributed to statistical analysis.

$\mathrm{YL}$ was the major contributor in drafting the manuscript.

$X Z$ and XDY critically revised the manuscript and approved the version to be submitted.

All authors read and approved the final manuscript.

\subsection{Acknowledgements}

Not applicable.

\subsection{Authors' information}

${ }^{1}$ Department of Intensive Care Medicine, Peking University Third Hospital, Beijing 100191, China;

${ }^{2}$ Department of Anesthesiology, Peking University Hospital of Stomatology, Beijing 100081, China.

\subsection{CONSORT Guidelines}

This manuscript reporting adhered to CONSORT guidelines.

\section{References}

1. Nijbroek SG, Schultz MJ, Hemmes SNT. Prediction of postoperative pulmonary complications. Curr Opin Anaesthesiol. 2019; 32: 443-51.

2. Eva K, Lars IE, Heidrun L, Malin JF, Andreas H, Markus H, et al. Post-anaesthesia pulmonary complications after use of muscle relaxants (POPULAR): a multicentre, prospective observational study. The Lancet Respiratory Medicine. 2019; 7: 129-40.

3. Bluth T, Serpa NA, Schultz MJ, Pelosi P, Gama de AM. Effect of Intraoperative High Positive EndExpiratory Pressure (PEEP) With Recruitment Maneuvers vs Low PEEP on Postoperative Pulmonary Complications in Obese Patients. Jama. 2019; 321: 2292-305. 
4. FRCA O, MAcadMEd T, FFICM R. Postoperative pulmonary complications following noncardiothoracic surgery. BJA Education. 2017; 17: 295-300.

5. Loeffelbein DJ, Julinek A, Wolff KD, Kochs E, Haller B, Haseneder R. Perioperative risk factors for postoperative pulmonary complications after major oral and maxillofacial surgery with microvascular reconstruction: A retrospective analysis of 648 cases. J Craniomaxillofac Surg. 2016; 44: 952-7.

6. Li L, Yuan W, Zhang S, Wang K, Ruan H. Analysis of Risk Factors for Pneumonia in 482 Patients Undergoing Oral Cancer Surgery with Tracheotomy. J Oral Maxillofac Surg. 2016; 74: 415-9.

7. Damian D, Esquenazi J, Duvvuri U, Johnson JT, Sakai T. Incidence, outcome, and risk factors for postoperative pulmonary complications in head and neck cancer surgery patients with free flap reconstructions. J Clin Anesth. 2016; 28: 12-8.

8. Petrar S, Bartlett C, Hart RD, MacDougall P. Pulmonary complications after major head and neck surgery: A retrospective cohort study. Laryngoscope. 2012; 122: 1057-61.

9. Ong SK, Morton RP, Kolbe J, Whitlock RM, Mclvor NP. Pulmonary Complications Following Major Head and Neck Surgery with Tracheostomy: A Prospective, Randomized, Controlled Trial of Prophylactic Antibiotics. Arch Otolaryngol Head Neck Surg. 2004; 130: 1084-87.

10. Su X, Meng ZT, Wu XH, Cui F, Li HL, Wang DX, et al. Dexmedetomidine for prevention of delirium in elderly patients after non-cardiac surgery: a randomised, double-blind, placebo-controlled trial. The Lancet. 2016; 388: 1893-902.

11. Davoudi A, Movahedian AB, Shadmehr E. Risks and benefits of pre-operative dexmedetomidine in oral and maxillofacial surgeries: a systematic review. Expert Opin Drug Saf. 2017; 16: 711-20.

12. Wang $\mathrm{K}, \mathrm{Wu} \mathrm{MG}, \mathrm{Xu} \mathrm{J}$, Wu CS, Zhang BH, Wang GN, et al. Effects of dexmedetomidine on perioperative stress, inflammation, and immune function: systematic review and meta-analysis. [J]. Br J Anaesth, 2019, 123: 777-794.

13. Lee SH, Kim N, Lee CY, Ban MG, Oh YJ. Effects of dexmedetomidine on oxygenation and lung mechanics in patients with moderate chronic obstructive pulmonary disease undergoing lung cancer surgery: A randomised double-blinded trial. Eur J Anaesthesiol. 2016; 33: 275-82.

14. Huang S, Zhang J, Zhang X, Liu L, Yu Y, Kang X, et al. Can Dexmedetomidine Improve Arterial Oxygenation and Intrapulmonary Shunt during One-lung Ventilation in Adults Undergoing Thoracic Surgery? A Meta-analysis of Randomized, Placebo-controlled Trials. Chinese Medical Journal. 2017; 130: 1707-14.

15. Soliman R, Zohry G. The myocardial protective effect of dexmedetomidine in high-risk patients undergoing aortic vascular surgery. [J]. Ann Card Anaesth, 2016, 19: 606-613.

16. Liu MY, Wang Z, Zhang Q, Xu G. Effect of Dexmedetomidine Hydrochloride on Perioperative Inflammatory Factors and Postoperative Pulmonary Complications in Elderly Patients Undergoing Spinal Surgery. Herald of Medicine. 2018; 37: 568-72.

17. Li X, Yang J, Nie XL, Zhang Y, Li XY, Li LH, et al. Impact of dexmedetomidine on the incidence of delirium in elderly patients after cardiac surgery: A randomized controlled trial. [J]. PLoS ONE, 2017, 
12: e0170757.

18. Zhang LY, Zhang YH, Shen J, Luo Y. Effects of dexmedetomidine on post-operative recovery and mental status in patients receiving robotic-assisted thoracic surgery. [J]. Ann Palliat Med, 2019, 8: 469-475.

19. Peng K, Li D, Applegate RL, Lubarsky DA, Ji FH, Liu H. Effect of Dexmedetomidine on Cardiac Surgery-Associated Acute Kidney Injury: A Meta-Analysis with Trial Sequential Analysis of Randomized Controlled Trials. [J]. J. Cardiothorac. Vasc. Anesth., 2020, 34: 603-613.

20. Canet J, Gallart L, Gomar C, Paluzie G, s JV, Castillo J, et al. Prediction of Postoperative Pulmonary Complications in a Population-based Surgical Cohort. Anesthesiology. 2010; 113: 1338-50.

21. Katayama H, Kurokawa Y, Nakamura K, Ito H, Kanemitsu Y, Masuda N, et al. Extended Clavien-Dindo classification of surgical complications: Japan Clinical Oncology Group postoperative complications criteria. Surg Today. 2016; 46: 668-85.

22. Xu J, Hu J, Yu P, Wang W, Hu X, Hou J, et al. Perioperative risk factors for postoperative pneumonia after major oral cancer surgery: A retrospective analysis of 331 cases. PLoS One. 2017; 12 : e0188167.

23. Meier J, Wunschel M, Angermann A, Ettl T, Metterlein T, Klingelhoffer C, et al. Influence of early elective tracheostomy on the incidence of postoperative complications in patients undergoing head and neck surgery. BMC Anesthesiol. 2019; 19: 43.

24. Zhang C, Xi MY, Zeng J, Li Y, Yu C. Prognostic Impact of Postoperative Complications on Overall Survival in 287 Patients with Oral Cancer: A

Retrospective Single-Institution Study. SURGICAL ONCOLOGY AND RECONSTRUCTION. 2019; 77: 147179.

25. An X, Sun X, Yang X, Liu D, Hou Y, Chen H, et al. Oxidative stress promotes ventilator-induced lung injury through activating NLRP3 inflammasome and TRPM2 channel. Artif Cells Nanomed Biotechnol. 2019; 47: 3448-55.

26. Xue BB, Chen BH, Tang YN, Weng CW, Lin LN. Dexmedetomidine protects against lung injury induced by limb ischemia-reperfusion via the TLR4/MyD88/NF-kappaB pathway. Kaohsiung J Med Sci. 2019.

27. Im Y, Park HY, Shin S, Shin SH, Lee H, Ahn JH, et al. Prevalence of and risk factors for pulmonary complications after curative resection in otherwise healthy elderly patients with early stage lung cancer. Respir Res. 2019; 20: 136.

28. Hammer G, Shafer SL. Playing with dexmedetomidine pharmacokinetics! [J]. Br J Anaesth, 2020, 124: $238-240$.

29. Wang K, Wu MG, Xu J, Wu CS, Zhang BH, Wang GN, et al. Effects of dexmedetomidine on perioperative stress, inflammation, and immune function: systematic review and meta-analysis. [J]. $\mathrm{Br} J$ Anaesth, 2019, 123: 777-794.

30. Duan GY, Wang K, Peng TT, Wu ZX, Li H. The Effects of Intraoperative Dexmedetomidine Use and Its Different Dose on Postoperative Sleep Disturbance in Patients Who Have Undergone Non-Cardiac 
Major Surgery: A Real-World Cohort Study. [J]. Nat Sci Sleep, 2020, 12: 209-219.

31. Deiner S, Luo XD, Lin HM, Lin HM, Sessler DI, Saager L, et al. Intraoperative Infusion of Dexmedetomidine for Prevention of Postoperative Delirium and Cognitive Dysfunction in Elderly Patients Undergoing Major Elective Noncardiac Surgery: A Randomized Clinical Trial. [J]. JAMA Surg, 2017, 152: e171505.

32. Wu XH, Cui F, Zhang C, Meng ZT, Wang DX, Ma J, et al. Low-dose Dexmedetomidine Improves Sleep Quality Pattern in Elderly Patients after Noncardiac Surgery in the Intensive Care Unit: A Pilot Randomized Controlled Trial. [J]. Anesthesiology, 2016, 125: 979-991.

33. Odor PM, Bampoe S, Gilhooly D, Brown BC, Moonesinghe SR. Perioperative interventions for prevention of postoperative pulmonary complications: systematic review and meta-analysis. [J]. BMJ, 2020, 368: m540.

34. Mazo V, Sabaté S, Canet J, Gallart L, Abreu MGD, Belda J, et al. Prospective external validation of a predictive score for postoperative pulmonary complications. Anesthesiology. 2014;121(2):219-231.

35. Zhang H, Sha J, Feng X, Hu X, Chen Y, Li B, et al. Dexmedetomidine ameliorates LPS induced acute lung injury via GSK-3beta/STAT3-NF-kappaB signaling pathway in rats. Int Immunopharmacol. 2019; 74: 105717.

36. Zhang DF, Su X, Meng ZT, Li HL, Wang DX, Li XY, et al. Impact of Dexmedetomidine on Long-term Outcomes After Noncardiac Surgery in Elderly: 3-Year Follow-up of a Randomized Controlled Trial. [J]. Ann. Surg., 2019, 270: 356-363.

37. Groeben H, Mitzner W, Brown RH. Effects of the a2-Adrenoceptor Agonist Dexmedetomidine on Bronchoconstriction in Dogs. Anesthesiology. 2004; 100: 359-63.

38. Mikami M, Zhang Y, Kim B, Worgall TS, Groeben H, Emala CW. Dexmedetomidine's inhibitory effects on acetylcholine release from cholinergic nerves in guinea pig trachea: a mechanism that accounts for its clinical benefit during airway irritation. BMC Anesthesiol. 2017; 17: 52.

39. Meng L, Li L, Lu S, Li K, Su Z, Wang Y, et al. The protective effect of dexmedetomidine on LPSinduced acute lung injury through the HMGB1-mediated TLR4/NF-kappaB and PI3K/Akt/mTOR pathways. Mol Immunol. 2018; 94: 7-17.

40. Zeng H, Li Z, He J, Fu W. Dexmedetomidine for the prevention of postoperative delirium in elderly patients undergoing noncardiac surgery: A meta-analysis of randomized controlled trials. PLoS One. 2019; 14: e0218088.

41. de la Gala F, Pineiro P, Reyes A, Vara E, Olmedilla L, Cruz P, et al. Postoperative pulmonary complications, pulmonary and systemic inflammatory responses after lung resection surgery with prolonged one-lung ventilation. Randomized controlled trial comparing intravenous and inhalational anaesthesia. Br J Anaesth. 2017; 119: 655-63.

42. Zhang Y, Du ZH, Zhou Q, Wang YL, Li JG. Remifentanil attenuates lipopolysaccharide-induced acute lung injury by downregulating the NF-KB signaling pathway. [J]. Inflammation, 2014, 37: 1654-60.

43. Zhang JN, Ma Y, Wei XY, Liu KY, Wang H, Han H, et al. KRemifentanil Protects against Lipopolysaccharide-Induced Inflammation through PARP-1/NF-B Signaling Pathway. [J]. Mediators 
Inflamm., 2019, 2019: 3013716.

44. Hasanin A, Taha K, Abdelhamid B, Abougabal A, Elsayad M, Refaie A, et al. Evaluation of the effects of dexmedetomidine infusion on oxygenation and lung mechanics in morbidly obese patients with restrictive lung disease. BMC Anesthesiol. 2018; 18: 104.

45. Abdul HB, Sbeitan SM, Shakya AK. Fentanyl vs fentanyl-dexmedetomidine in lumbar foraminotomy surgery. Ther Clin Risk Manag. 2019; 15: 885-90.

46. Weina L, Qinghui F, Xlaoqian L, Fu S, Hu K. Effects of dexmedetomidine on sleep quality of patients after surgery without mechanical ventilation in ICU. Medicine. 2017; 96: e7081.

\section{Tables}

Table 1: Baseline Patient Demographic and Preoperative Characteristics 


\begin{tabular}{|c|c|c|c|}
\hline Characteristic & $\begin{array}{l}\text { Dexmedetomidine group } \\
\qquad(\mathrm{n}=80)\end{array}$ & $\begin{array}{l}\text { Placebo group } \\
\qquad(\mathrm{n}=80)\end{array}$ & $P$ value \\
\hline Age, median (IQR), year & $59(55,65)$ & $62(56,67)$ & 0.123 \\
\hline \multicolumn{4}{|l|}{ Sex, No. (\%) } \\
\hline Male & $51(63.8)$ & $53(66.3)$ & 0.740 \\
\hline Female & $29(36.3)$ & $27(33.8)$ & \\
\hline Hight, median (IQR), cm & $168.0(160.0,171.5)$ & $166.00(160.0,172.0)$ & 0.832 \\
\hline Weight, median (IQR), kg & $60.50(55.0,69.5)$ & $62.00(57.5,71.0)$ & 0.284 \\
\hline BMI, median (IQR) ${ }^{a}$ & $22.59(20.36,24.16)$ & $22.90(21.03,25.10)$ & 0.283 \\
\hline \multicolumn{4}{|l|}{ ARISCAT score ${ }^{b}$} \\
\hline Intermediate risk, No. (\%) & $77(96.3)$ & $79(98.8)$ & 0.311 \\
\hline High risk, No. (\%) & $3(3.8)$ & $1(1.3)$ & \\
\hline Mean (SD) & $28.36(4.82)$ & $28.32(4.81)$ & \\
\hline \multicolumn{4}{|l|}{ ASA physical status classification, No. (\%) ${ }^{c}$} \\
\hline 1 & $16(20.0)$ & $17(21.3)$ & 0.216 \\
\hline 2 & $61(76.3)$ & $63(78.7)$ & \\
\hline 3 & $3(3.8)$ & $0(0)$ & \\
\hline \multicolumn{4}{|l|}{ NYHA heart failure class, No. (\%) ${ }^{d}$} \\
\hline I & $47(58.8)$ & $51(63.7)$ & 0.516 \\
\hline II & $33(41.2)$ & $29(36.2)$ & \\
\hline Tobacco use, No. (\%) & $31(38.8)$ & $29(36.2)$ & 0.744 \\
\hline Alcohol use, No. (\%) ${ }^{\mathrm{e}}$ & $25(31.3)$ & $21(26.3)$ & 0.485 \\
\hline \multicolumn{4}{|l|}{ Preoperative $\mathrm{SpO}_{2}$, No. (\%) } \\
\hline$\geq 96$ & $67(83.8)$ & $68(85.0)$ & 0.975 \\
\hline $91-95$ & $12(15.0)$ & $11(13.8)$ & \\
\hline$\leq 90$ & $1(1.3)$ & $1(1.3)$ & \\
\hline Preoperative anemia $(\mathrm{Hb} \leq 10 \mathrm{~g} / \mathrm{dl})$, No. (\%) & $9(11.3)$ & $5(6.3)$ & 0.263 \\
\hline Mean (SD), g/dl & $13.54(2.03)$ & $13.72(1.92)$ & \\
\hline \multicolumn{4}{|l|}{ Comorbidity } \\
\hline Arterial hypertension, No. (\%) & $27(33.8)$ & $24(30.0)$ & 0.611 \\
\hline Diabetes, No. (\%) & $9(11.3)$ & $12(15.0)$ & 0.483 \\
\hline Coronary artery disease, No. (\%) & $8(10.0)$ & $4(5.0)$ & 0.230 \\
\hline Arrhythmia, No. (\%) & $6(7.5)$ & $6(7.5)$ & 1.000 \\
\hline COPD, No. (\%) & $1(1.3)$ & $4(5.0)$ & 0.173 \\
\hline Asthma, No. (\%) & $0(0.0)$ & $1(1.3)$ & 0.316 \\
\hline Preoperative abnormalities on chest radiography, No. (\%) & $4(5.0)$ & $8(10.0)$ & 0.230 \\
\hline Active cancer, No. (\%) & $69(86.3)$ & $70(87.5)$ & 0.815 \\
\hline
\end{tabular}

Abbreviations: IQR, interquartile range; BMI, body mass index; ARISCAT, Assess Respiratory Risk in Surgical Patients in Catalonia; ASA, American Society of Anesthesiology; NYHA, New York Heart Association; $\mathrm{SpO}_{2}$, oxygen saturation as measured by pulse oximetry; Hb, Hemoglobin; COPD, chronic obstructive pulmonary disease.

${ }^{a}$ Calculated as weight in kilograms divided by height in meters squared. 
${ }^{b}$ Score range is from 0 to 123; higher scores indicate a higher risk of postoperative pulmonary complications. Patients with scores of 26 to 44 are considered at intermediate risk; those with scores more than 44 are considered at high risk.

${ }^{c}$ Score range is from 1 to 6 and includes a classification for normal health as 1; mild systemic disease, 2; severe systemic disease, 3; severe systemic disease that is a constant threat to life, 4 . patients with scores of 5 or 6 were excluded.

${ }^{d}$ Score range is from I to IV; higher scores indicate a higher extent of heart failure. Patients without limitation of their ordinary physical activity are classified NYHA class I; those with slight limitation of their activity are classified as NYHA class II. Patients with scores of III or IV were excluded.

${ }^{e}$ Defined as more than 2 drinks per day during the past 2 weeks.

Table 2: Intraoperative Characteristics

\begin{tabular}{|c|c|c|c|}
\hline \multirow[t]{2}{*}{ Characteristic } & Dexmedetomidine group & Placebo group & \multirow[t]{2}{*}{$P$ value } \\
\hline & $(\mathrm{n}=80)$ & $(\mathrm{n}=80)$ & \\
\hline \multicolumn{4}{|l|}{ Cervical lymph node dissection, No. (\%) } \\
\hline No & $17(21.2)$ & $15(18.8)$ & 0.719 \\
\hline Unilateral & $45(56.3)$ & $50(62.5)$ & \\
\hline Bilateral & $18(22.5)$ & $15(18.7)$ & \\
\hline Duration of surgery, median (IQR), $\min ^{\mathrm{a}}$ & $330(275,382)$ & $310(263,393)$ & 0.386 \\
\hline Duration of anesthesia, median (IQR), $\min ^{\mathrm{b}}$ & $362(302,428)$ & $358(298,442)$ & 0.732 \\
\hline Duration of limb ischemia time, median (IQR), $\min ^{\mathrm{c}}$ & $59(53,71)$ & $60(50,68)$ & 0.611 \\
\hline Vital volume, median (IQR), ml & $425(400,450)$ & $425(400,450)$ & 0.860 \\
\hline Respiratory rate, median (IQR), breaths/ min & $12(12,13)$ & $12(12,14)$ & 0.905 \\
\hline \multicolumn{4}{|l|}{ Peak pressure, median (IQR), $\mathrm{cmH}_{2} \mathrm{O}$} \\
\hline After intubation & $15(13,16)$ & $14(13,16)$ & 0.281 \\
\hline The highest during the surgery & $16(14,18)$ & $16(14,18)$ & 0.989 \\
\hline Before the end of the surgery & $15(14,17)$ & $15(14,17)$ & 0.664 \\
\hline $\mathrm{FiO}_{2}$, median (IQR) & $50(50,50)$ & $50(50,50)$ & 0.277 \\
\hline \multicolumn{4}{|l|}{ Intraoperative medication, median (IQR) } \\
\hline Sufentanil, $\mu \mathrm{g}$ & $30(20,40)$ & $30(25,45)$ & 0.083 \\
\hline Propofol, mg & $1200(1000,1500)$ & $2500(2000,2700)$ & 0.000 \\
\hline Remifentanil, $\mu \mathrm{g}$ & $1450(1000,1980)$ & $2625(1700,3000)$ & 0.000 \\
\hline Dexmedetomidine, $\mu \mathrm{g}$ & $188(168,200)$ & $0(0,0)$ & 0.000 \\
\hline Crystalloids, median (IQR), ml & $1700(1700,2200)$ & $1700(1600,2200)$ & 0.947 \\
\hline Synthetic colloids, median (IQR), ml & $500(500,500)$ & $500(500,500)$ & 0.149 \\
\hline Estimated blood loss during surgery, median (IQR), ml & $300(200,400)$ & $300(200,350)$ & 0.508 \\
\hline Urine output, median (IQR) & $675(400,900)$ & $500(350,700)$ & 0.016 \\
\hline Total intraoperative infusion, median (IQR), ml & $1450(1000,1900)$ & $1450(1075,1875)$ & 0.895 \\
\hline
\end{tabular}

Abbreviations: $\mathrm{FiO}_{2}$, fraction of inspired oxygen.

${ }^{a}$ Calculated as the time between skin incision and closure of the incision.

${ }^{b}$ Calculated as the time from the start of induction to the patient leaving the operating room. 
${ }^{c}$ Calculated as the time from the beginning of inflation to the end of exhalation of the tourniquet in the thigh.

Table 3: Postoperative Characteristics

\begin{tabular}{|c|c|c|c|}
\hline \multirow[t]{2}{*}{ Characteristic } & Dexmedetomidine group & Placebo group & \multirow[t]{2}{*}{$\mathrm{P}$ value } \\
\hline & $(n=80)$ & $(\mathrm{n}=80)$ & \\
\hline Length of stay in PACU, median (IQR), min & $855(675,970)$ & $923(730,1020)$ & 0.073 \\
\hline \multicolumn{4}{|l|}{ Medication in PACU, median (IQR), min } \\
\hline Dexmedetomidine in PACU & $168(160,184)$ & $0(0,0)$ & 0.000 \\
\hline Total Dexmedetomidine on operation day ${ }^{a}$ & $360(338,378)$ & $0(0,0)$ & 0.000 \\
\hline Sufentanil in PACU & $0(0,0)$ & $0(0,0)$ & 0.100 \\
\hline Total sufentanil on operation day ${ }^{a}$ & $30(25,40)$ & $34(25,46)$ & 0.070 \\
\hline Time with tracheotomy tube, median (IQR), $d$ & $5(5,6)$ & $5(5,6)$ & 0.551 \\
\hline \multicolumn{4}{|l|}{ Total infusion, mean (SD), ml } \\
\hline The operation day ${ }^{a}$ & $1848.65 \pm 622.996$ & $1888.44 \pm 690.296$ & 0.702 \\
\hline The first day after surgery & $931.69 \pm 1108.510$ & $989.25 \pm 1098.572$ & 0.742 \\
\hline The second day after surgery & $861.04 \pm 954.420$ & $868.41 \pm 1162.951$ & 0.717 \\
\hline \multicolumn{4}{|c|}{ NRS for oral and maxillofacial area pain, mean (SD) } \\
\hline The first day after surgery & $1.30 \pm 1.226$ & $3.20 \pm 1.363$ & 0.000 \\
\hline The second day after surgery & $1.49 \pm 1.534$ & $1.53 \pm 1.492$ & 0.876 \\
\hline The Third day after surgery & $1.39 \pm 1.497$ & $1.44 \pm 1.231$ & 0.818 \\
\hline \multicolumn{4}{|l|}{ NRS for fibular area pain, mean (SD) } \\
\hline The first day after surgery & $1.59 \pm 1.357$ & $3.71 \pm 1.070$ & 0.000 \\
\hline The second day after surgery & $1.49 \pm 1.369$ & $1.58 \pm 1.367$ & 0.686 \\
\hline The third day after surgery & $1.55 \pm 1.457$ & $1.43 \pm 1.261$ & 0.563 \\
\hline \multicolumn{4}{|l|}{ Sleep time, median (IQR), $\mathrm{h}$} \\
\hline The first day after surgery & $6.0(5.0,7.0)$ & $4.0(3.3,5.0)$ & 0.000 \\
\hline The second day after surgery & $5.0(4.3,6.0)$ & $5.0(4.0,6.0)$ & 0.520 \\
\hline
\end{tabular}

Abbreviations: PACU, post anesthesia care unit; NRS, numeric rating scale.

${ }^{a}$ Defined the time from the beginning of the surgery to the next morning $0800 \mathrm{~h}$ in PACU.

Table 4: Primary and Secondary Outcomes 


\begin{tabular}{|c|c|c|c|c|}
\hline \multirow[t]{2}{*}{ Outcome } & \multirow{2}{*}{$\begin{array}{c}\text { Dexmedetomidine } \\
\text { group }\end{array}$} & \multirow{2}{*}{$\begin{array}{l}\text { Placebo } \\
\text { group } \\
(n=80)\end{array}$} & Relative risk & \multirow[t]{2}{*}{$\begin{array}{c}\mathrm{P} \\
\text { value }\end{array}$} \\
\hline & & & $(95 \% \mathrm{CI})$ & \\
\hline \multicolumn{5}{|l|}{ Primary outcome, No. (\%) } \\
\hline Overall incidence of PPCs & $18(22.5)$ & $32(40.0)$ & $\begin{array}{l}0.563(0.346- \\
0.916)\end{array}$ & 0.017 \\
\hline Respiratory infection & $14(17.5)$ & $19(23.8)$ & $\begin{array}{l}0.737(0.398- \\
1.356)\end{array}$ & 0.329 \\
\hline Respiratory failure & $3(3.8)$ & $7(8.8)$ & $\begin{array}{l}0.429(0.115- \\
1.599)\end{array}$ & 0.191 \\
\hline Pleural effusion & $0(0)$ & $2(2.5)$ & -- & 0.155 \\
\hline Atelectasis & $1(1.3)$ & $5(6.3)$ & $\begin{array}{l}0.200(0.024- \\
1.674)\end{array}$ & 0.096 \\
\hline Pneumothorax & $0(0)$ & $0(0)$ & -- & - - \\
\hline Bronchospasm & $0(0)$ & $1(1.3)$ & -- & 0.316 \\
\hline Aspiration pneumonitis & $0(0)$ & $0(0)$ & - & - \\
\hline Pulmonary edema & $1(1.3)$ & $2(2.5)$ & $0.500(0.046-5.404)$ & 0.560 \\
\hline Pulmonary embolism & $1(1.3)$ & $1(1.3)$ & $\begin{array}{l}1.000(0.064- \\
15.712)\end{array}$ & 1.000 \\
\hline Acute respiratory distress syndrome & $1(1.3)$ & $0(0)$ & -- & 0.316 \\
\hline \multicolumn{5}{|l|}{ Secondary outcome, No. (\%) } \\
\hline The time to first diagnosis of PPCs ${ }^{a}$ & $4(2,5)$ & $3(2,5)$ & - & 0.928 \\
\hline \multicolumn{5}{|l|}{ The number of PPCs ${ }^{b}$} \\
\hline 0.00 & $62(77.5)$ & $48(60.0)$ & -- & - - \\
\hline 1.00 & $15(18.8)$ & $27(33.8)$ & $\begin{array}{l}0.541(0.314- \\
0.933)\end{array}$ & 0.023 \\
\hline 2.00 & $3(3.8)$ & $5(6.3)$ & $\begin{array}{l}0.489(0.123- \\
1.954)\end{array}$ & 0.300 \\
\hline \multicolumn{5}{|l|}{ postoperative extrapulmonary complications ${ }^{\mathrm{C}}$} \\
\hline Delirium & $1(1.3)$ & $4(5.0)$ & $\begin{array}{l}0.250(0.029- \\
2.188)\end{array}$ & 0.173 \\
\hline Anemia $^{d}$ & $3(3.8)$ & $2(2.5)$ & $\begin{array}{l}1.500(0.258- \\
8.737)\end{array}$ & 0.650 \\
\hline Extrapulmonary infection & $2(2.5)$ & $4(5.0)$ & $0.500(0.094-2.653)$ & 0.405 \\
\hline Need secondary surgery ${ }^{e}$ & $4(5.0)$ & $6(7.5)$ & $\begin{array}{c}0.667(0.196- \\
2.273)\end{array}$ & 0.514 \\
\hline \multicolumn{5}{|l|}{ Adverse events } \\
\hline Bradycardia $^{f}$ & $2(2.5)$ & $2(2.5)$ & -- & 1 \\
\hline Hypotension ${ }^{g}$ & $2(2.5)$ & $3(3.8)$ & $\begin{array}{l}0.667(0.114- \\
3.883)\end{array}$ & 0.650 \\
\hline $\begin{array}{l}\text { Length of stay in hospital after surgery, median } \\
\text { (IQR), day }\end{array}$ & $9(8,11)$ & $10(9,11)$ & -- & 0.036 \\
\hline 30-day all-cause mortality & $0(0.0)$ & $0(0.0)$ & - & 1 \\
\hline
\end{tabular}


Abbreviations: PPCs, postoperative pulmonary complications.

${ }^{a}$ Indicated the time from end of surgery to first diagnosis of PPCs within 7 days after surgery.

${ }^{b}$ Indicated the number of diagnosed individual PPCs within 7 days after surgery.

${ }^{c}$ Defined as complications other than PPCs that occur during operation and within 7 days after surgery, and require therapeutic intervention.

${ }^{d}$ Defined as hemoglobin less than $9 g / d L$.

${ }^{e}$ Included hematoma or vascular crisis exploration within 7 days after surgery.

${ }^{f}$ Defined as heart rate less than 50 beats/min or a decrease of more than $20 \%$ from baseline.

${ }^{g}$ Defined as systolic blood pressure less than $90 \mathrm{~mm} \mathrm{Hg}$ or a decrease of more than $20 \%$ from baseline.

Table 5: Log rank test of the time to onset of PPCs between two groups

\begin{tabular}{lrccr}
\hline Groups & Mean & SE & \multicolumn{3}{c}{ 95\% Confidence Interval } & P value \\
\cline { 2 - 4 } & & \multicolumn{4}{c}{ Lower Bound Upper Bound } \\
\hline Dexmedetomidine group 6.212 0.191 & 5.837 & 6.588 & 0.019 \\
\cline { 1 - 4 } Placebo group & 5.6250 .219 & 5.196 & 6.054 & \\
\hline Overall & 5.9190 .146 & 5.633 & 6.204 & \\
\hline
\end{tabular}

Table 6: Cox regression of PPCs between two groups

\begin{tabular}{|c|c|c|c|c|}
\hline Groups & B & Wald P value & HR & $\begin{array}{c}95.0 \% \text { CI } \\
\text { Lower Upper }\end{array}$ \\
\hline Dexmedetomidine group & -0.662 & 0.2955 .0350 .025 & 0.516 & $0.290 \quad 0.920$ \\
\hline Placebo group & reference & & & \\
\hline
\end{tabular}

Table 7: The Area Under ROC curve and Youden Index

\begin{tabular}{|c|c|}
\hline Area under ROC curve & 0.614 \\
\hline Std. Error & 0.0441 \\
\hline 95\% confidence interval & $0.534-0.690$ \\
\hline P valuelarea $=0.5 \square$ & 0.0094 \\
\hline Youden Index & $0 \square 2709$ \\
\hline cutoff & $\leq 328$ \\
\hline sensibility & 78.00 \\
\hline specificity & 49.09 \\
\hline
\end{tabular}




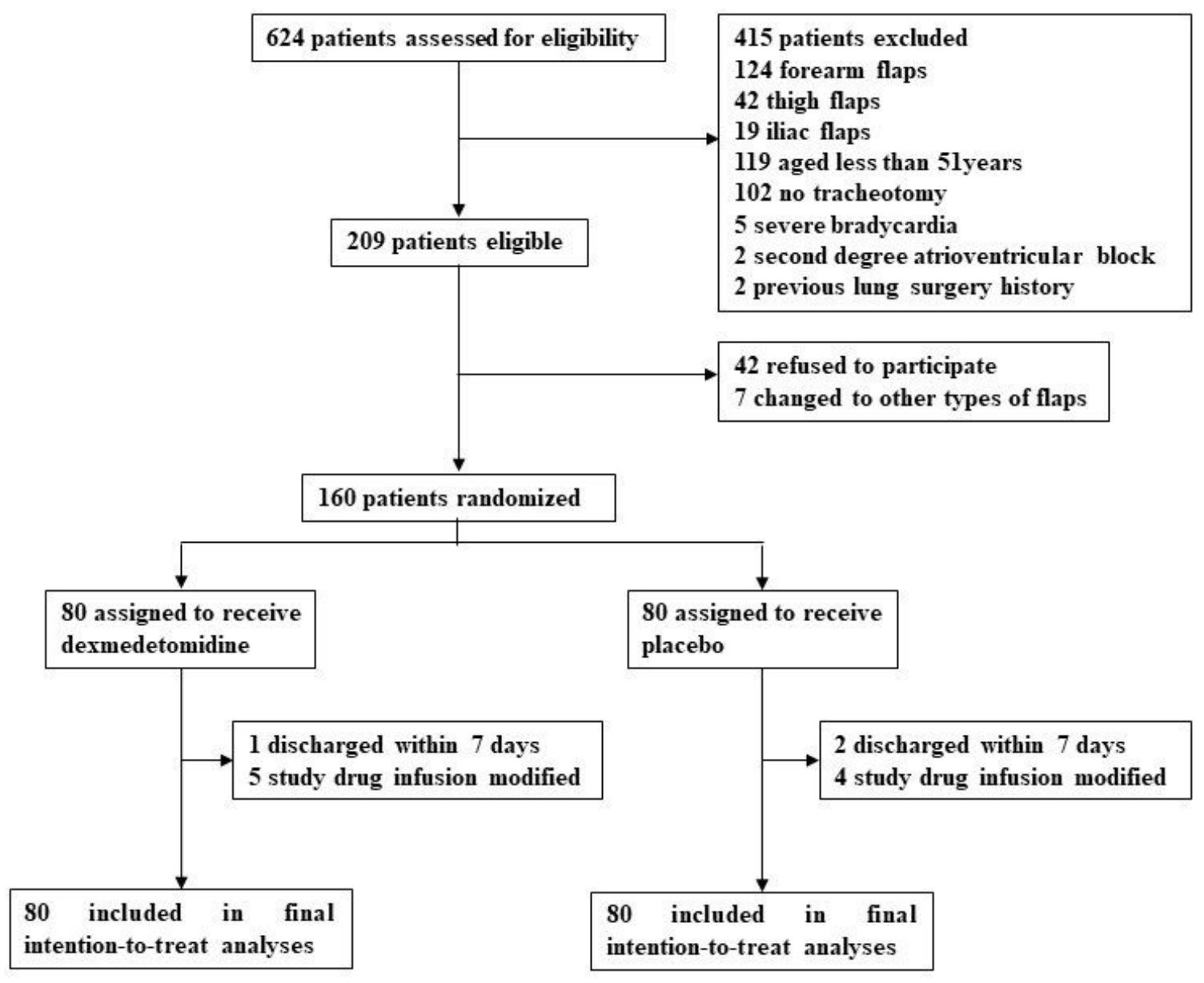

\section{Figure 1}

Flow Diagram of Patients Through Trial 


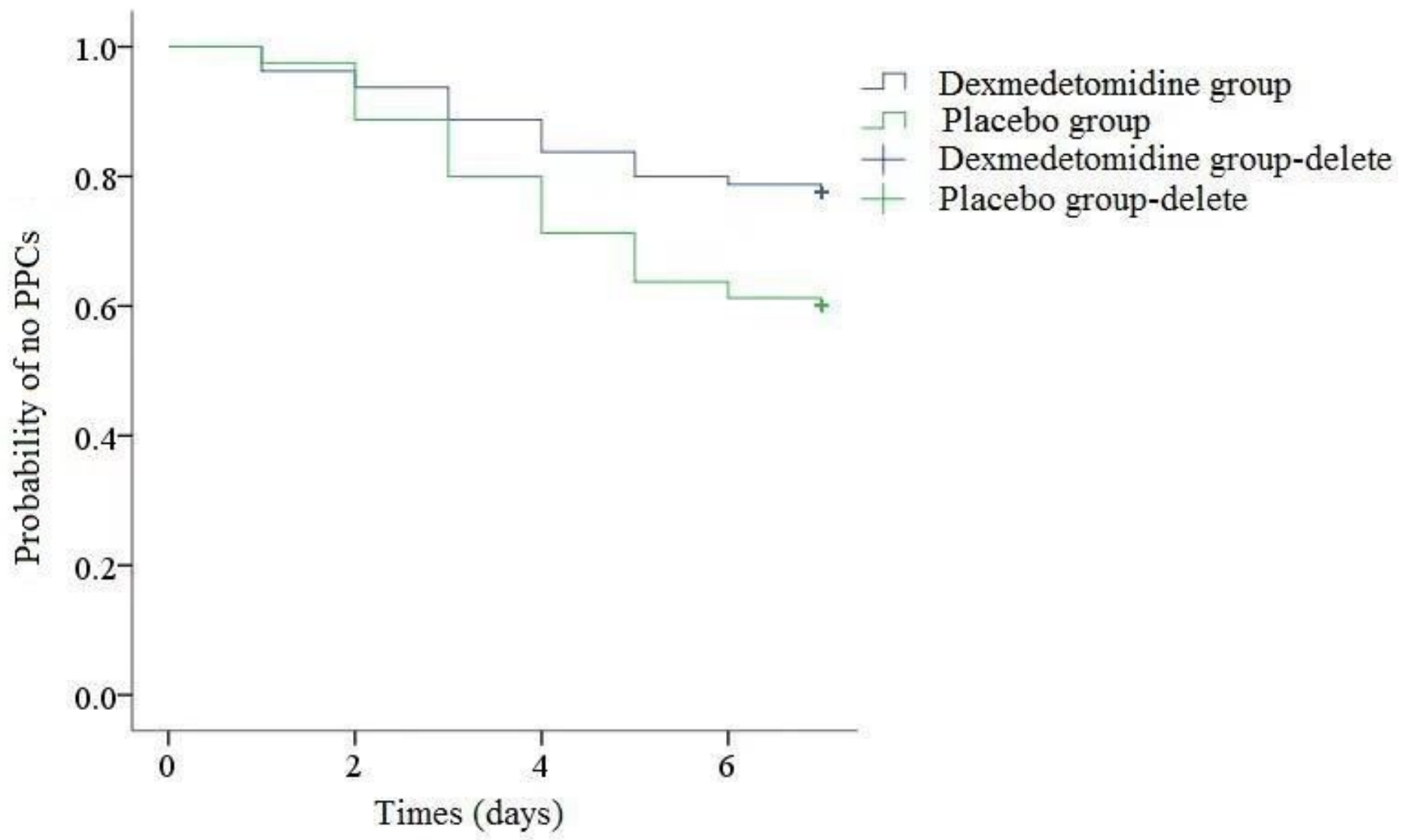

Figure 2

The Kaplan-Meier curve representing the time to occurrence of PPCs in the postoperative 7 days between the DEX group and the placebo group 


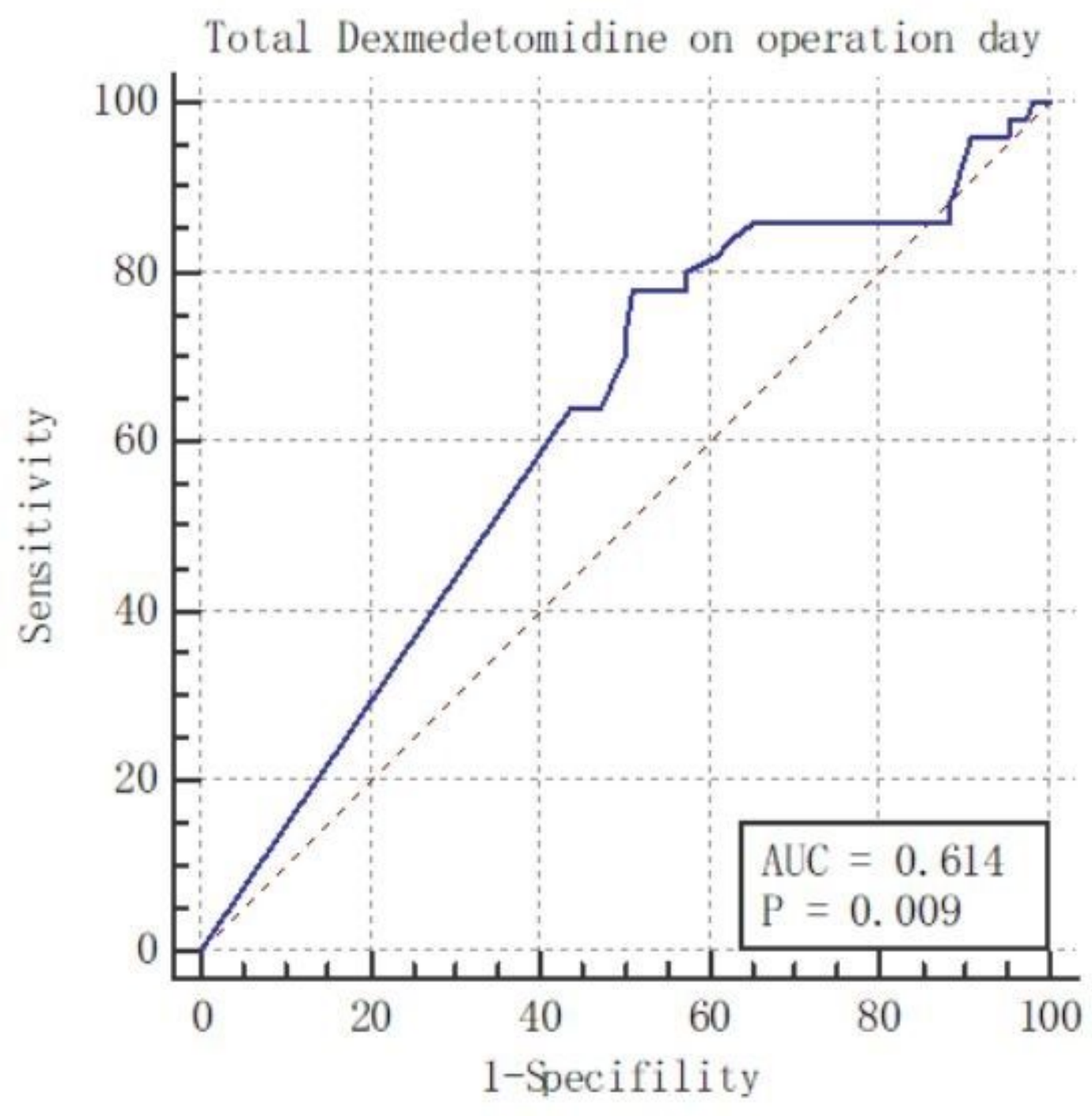

Figure 3

The ROC curve representing the relationship between total dose of DEX and the incidence of PPCs in the postoperative 7 days

\section{Supplementary Files}

This is a list of supplementary files associated with this preprint. Click to download.

- Aditionalfile2.pdf

- Aditionalfile3.pdf

- Aditionalfile1.pdf

- CONSORT2010Checklist.doc 